\title{
QS-21: A Potent Vaccine Adjuvant
}

\section{Daming $\mathrm{Zhu}^{1 *}$ and Wenbin Tuo ${ }^{2}$}

${ }^{1}$ Laboratory of Malaria Immunology and Vaccinology, National Institute of Allergy and Infectious Disease, National Institutes of Health, 5640 Fishers Lane, Rockville, MD 20852, USA

${ }^{2}$ Animal Parasitic Diseases Laboratory, Agricultural Research Service, USDA, Beltsville, MD 20705, USA

QS-21 is one of the active fractions of the bark of Chilean tree, Quillaja saponaria, purified using a reverse-phase chromatography (RP-HPLC) [1-3]. QS denotes its source as Q. saponaria and the number 21 as the identity of the RP-HPLC peak [2]. QS-21 is an acylated 3,28-bisdesmodic triterpene glycosides $(1,3)$ or "saponin" with a molecular formula of $\mathrm{C}_{92} \mathrm{O}_{46} \mathrm{H}_{148}$ and molecular weight of 1990 $\mathrm{Da}$ [1]. It is one of the most potent immunological adjuvants that has been widely used [4-8].

The adjuvant effect of saponins was first reported in 1925, when it was shown that the addition of bread crumbs, tapioca, saponin and "starch oil" to antigenic preparations greatly enhanced antibody responses to diphtheria or tetanus [7,9-11]. In 1951, Espinet used a crude commercially available saponin preparation to increase the potency of foot-and-mouth disease vaccines [10,12]. Further in 1974, Dalsgaard successfully isolated saponin Quil A from the cortex of the South-American Tree Quillaja saponaria Molina [3,13-15] and found that Quil A stimulated both humoral and cellular immunity, as well as induced differential antibody isotypes [3, 6,15-17]. Since then, the Quil A has been commercialized and has gained widespread use in veterinary vaccines and pre-clinical studies [3,6,10,14,17-20]. Additional studies showed its effects when co-formulated with aluminum salts, liposomes and oil-in-water emulsions, and with amphipathic proteins and lipids forming detergent/lipid/saponin complexs termed immune-stimulating complexes (ISCOMs) [3,20-23]. However, Quil A is still a heterogeneous product, consisting of up to 23 different saponin peaks detectable by HPLC and its toxicity precluded its use in human vaccines $[2-3,6,15,24]$.

Due to the fact that Quil A is a mixture, a further study was performed by Kensil et al. in 1991[2,6], in which 10 of RP-HPLC fractions from aqueous extract of $Q$. saponaria bark treated by ultrafiltration were tested and found the fractions QS-7, QS-17, QS-18 and QS-21 to be particularly potent. However, their toxicity varies considerably. QS-18, the major component of $Q$ saponaria, was found to be highly toxic in mice, while QS-7 and QS- 21 shows far less toxicity $[2,6,25]$. QS-21 was further extensive studied because it is more abundant than QS-7 [7].

Studies showed that QS-21 promoted high antigen-specific antibody responses and $\mathrm{CD}^{+} \mathrm{T}$-cell response in mice $[2-6,17,26]$ and favored a balanced production of both IgG1 and IgG2a [1,2,27]; in contrast, aluminum hydroxide mainly promotes IgG1 production $[2,6,27]$. Further studies showed that QS-21 stimulated the production of cytotoxic T-lymphocytes (CTLs), induces Thlcytokines, interleukin-2 and interferon-gamma (IL-2 and IFN- $\gamma$ ), and antibodies of the IgG2a isotype to protein antigens $[1,6,26,28,29]$. A number of comparative studies has demonstrated that QS-21 significantly outperformed the other classes of adjuvants including glucan formulations, peptidoglycans, amphophilic block copolymers, bacterial nucleosides and bacterial lipopolysaccharides, in augmenting antibody responses as well as T-cell responses against target antigens [2,7].

Due to the high potency, QS-21 has been used as an effective adjuvant with a recombinant retroviral subunit vaccine against feline leukemia virus (FeLV), which is commercially available now $[3,6,30]$.

However, the toxicity and the undesirable haemolytic effect still remain for human use [2,6,7]. QS-21 caused 50\% haemolysis of sheep red blood cells (SRBC) at concentrations as low as 7-9 $\mu \mathrm{g} / \mathrm{ml}(2$, 29), and apparently, the side effects associated with QS-21 limit doses to about $50 \mu \mathrm{g}$ with exception of cancer patient (melanoma, breast and prostate) [1,7]. It is clear that if the higher doses of this adjuvant could be safely used, its immunogenicity should be further increased [2,7]. The Adjuvant System (AS) developed by GlaxoSmithKline demonstrated that the apparent adverse events of QS-21 in rat skeletal muscle could be significantly reduced if QS-21 was formulated in AS01 (composed of liposomes, MPL and QS-21) at a dose of $5 \mu \mathrm{g}$, when compared to formulations containing QS-21 alone at the same dose, suggesting that the toxicity of QS-21 can be reduced when formulated with other appropriate adjuvants [5].

QS-21 containing adjuvants such as AS01, AS02 are currently tested in human clinical trials for various vaccine candidates and infectious agents, including influenza, malaria, hepatitis B virus (HBV), human papillomavirus (HPV), HIV/AIDS, tuberculosis (TB), non-small-cell lung carcinoma (NSCLC) and melanoma $[1,4,5,8,17,28]$.

Over the past two decades, the saponin adjuvants have emerged as one of the leading adjuvant candidates. QS-21 containing complex adjuvants in particular have been widely popular in its application to develop vaccines platforms [4,5,7]. It is promising that these QS-21 containing complex adjuvants may be one of the first to be approved as alternative adjuvants in human use in the US in the future.

\section{Acknowledgements}

Daming Zhu is supported by the Intramural Research Program of the National Institute of Allergy and Infectious Diseases, National Institutes of Health, Wenbin Tuo is supported by USDA/ARS.

\section{References}

1. Kensil CR, Kammer R (1998) QS-21: A water-soluble triterpene glycoside adjuvant. Expert Opin Investig Drugs 7: 1475-1482.

2. Kensil CR, Patel U, Lennick M, Marciani D (1991) Separation and characterization of saponins with adjuvant activity from Quillaja saponaria Molina cortex. J Immunol 146: 431-437.

3. Kensil CR (1996) Saponins as vaccine adjuvants. Crit Rev Ther Drug Carrier Syst 13: 1-55.

4. Garçon N, Van Mechelen M (2011) Recent clinical experience with vaccines using MPL- and QS-21-containing adjuvant systems. Expert Rev Vaccines 10: 471-486.

5. Garçon N, Chomez P, Van Mechelen M (2007) GlaxoSmithKline Adjuvant Systems in vaccines: Concepts, achievements and perspectives. Expert Rev Vaccines 6: 723-739.

6. Sun HX, Xie Y, Ye YP (2009) Advances in saponin-based adjuvants. Vaccine 27: 1787-1796.

*Corresponding author: Daming Zhu, Laboratory of Malaria Immunology and Vaccinology, National Institute of Allergy and Infectious Disease, National Institutes of Health, 5640 Fishers Lane, Rockville, MD 20852, USA, Tel: (301) 761-3993; E-mail: dzhu@niaid.nih.gov

Received July 27, 2015; Accepted July 28, 2015; Published August 02, 2015

Citation: Zhu D, Tuo W (2015) QS-21: A Potent Vaccine Adjuvant. Nat Prod Chem Res 3: e113. doi:10.4172/2329-6836.1000e113

Copyright: (C) 2015 Zhu D, et al. This is an open-access article distributed under the terms of the Creative Commons Attribution License, which permits unrestricted use, distribution, and reproduction in any medium, provided the original author and source are credited. 
7. Ragupathi G, Gardner JR, Livingston PO, Gin DY (2011) Natural and synthetic saponin adjuvant QS-21 for vaccines against cancer. Expert Rev Vaccines 10: 463-470.

8. Lee S, Nguyen MT (2015) Recent advances of vaccine adjuvants for infectious diseases. Immune Network 15: 51-57.

9. Ramon G (1925) Sur L'augmentation anormale de L'antitoxine chez les chevaux producteurs de serum antidiphtherique. Bull Soc Centr Med Vet 101: 227-234.

10. Dalsgaard K (1978) A study of the isolation and characterization of the saponin Quil A. Evaluation of its adjuvant activity, with a specia reference to the application in the vaccination of cattle against foot-andmouth disease. Acta Vet Scand Suppl 69: 7-40.

11. Warshakoon HJ, Hood JD, Kimbrell MR, Malladi S, Wu WY, et al. (2009) Potential adjuvantic properties of innate immune stimuli. Hum Vaccines 5 : 381-394

12. Espinet RG (1951) Nouveau vaccin antiaphteux a complexe glucoviral. Gac Vet (B. Aires) 13: 268

13. Dalsgaard K (1974) Saponin adjuvants. III. Isolation of a substance from Quillaja saponaria Molina with adjuvant activity in food-and-mouth disease vaccines. Arch Gesamte Virusforsch 44: 243-254.

14.Dalsgaard K, Jensen MH, Sorensen KJ (1977) Saponin adjuvants. IV Evaluation of the adjuvant quil $A$ in the vaccination of cattle against foot-andmouth disease. Acta Vet Scand 18: 349-360.

15. Campbell JB, Peerbaye YA (1992) Saponin. Res Immunol 143: 526-530

16. Kenney JS, Hughes BW, Masada MP, Allison AC (1989) Influence of adjuvants on the quantity, affinity, isotype and epitope specificity of murine antibodies. J Immunol Methods 121: 157-166.

17. Song X, Hu S (2009) Adjuvant activities of saponins from traditional Chinese medicinal herbs. Vaccine 27: 4883-4890.

18. Borja GPC, Correia NNP, Silva VOD, Paraguai SED, Santos WR, et al. (2002) Long lasting protection against canine kala-azar using the FML-QuilA saponin vaccine in an endemic area of Brazil (São Gonçalo do Amarante, RN). Vaccine 20: $3277-3284$.
19. Dalsgaard K, Jensen MH (1977) Saponin adjuvants. VI. The adjuvant activity of quil $A$ in trivalent vaccination of cattle and guinea pigs against foot-and-mouth disease. Acta Vet Scand 18: 367-373.

20. Kirk DD, Rempel R, Pinkhasov J, Walmsley AM (2004) Application of Quillaja saponaria extracts as oral adjuvants for plant-made vaccines. Expert Opin Bio Ther 4: 947-958.

21. Hu KF, Lövgren-Bengtsson K, Morein B (2001) Immunostimulating complexes (ISCOMs) for nasal vaccination. Adv Drug Deliv Rev 51: 149-159.

22. Morein B, Hu KF, Abusugra I (2004) Current status and potential application of ISCOMs in veterinary medicine. Adv Drug Deliv Rev 56: 1367-1382.

23. Kersten G, Hirschberg H (2004) Antigen delivery systems. Expert Rev Vaccines 3: 453-462.

24. Aguilar JC, Rodríguez EG (2007) Vaccine adjuvants revisited. Vaccine 25 3752-3762.

25. Kensil CR, Wu JY, Anderson CA, Wheeler DA, Amsden J (1998) QS-21 and QS-7: Purified saponin adjuvants. J Dev Biol Stand 92: 41-47.

26. Singh $\mathrm{M}^{1}$, O'Hagan DT (2003) Recent advances in veterinary vaccine adjuvants Int J Parasitol 33: 469-478.

27. Katayama S, Oda K, Ohgitani T, Hirahara T, Shimizu Y (1999) Influence of antigenic forms and adjuvants on the IgG subclass antibody response to Aujeszky's disease virus in mice. Vaccine 17: 2733-2739.

28. O'Hagan DT, MacKichan ML, Singh M (2001) Recent developments in adjuvants for vaccines against infectious diseases. Biomol Eng 18: 69-85.

29. Liu G, Anderson C, Scaltreto H, Barbon J, Kensil CR (2002) QS-21 structure/ function studies: effect of acylation on adjuvant activity. Vaccine 20:2808-2315

30. Marciani DJ, Kensil CR, Beltz GA, Hung CH, Cronier J, et al. (1991) Geneticallyengineered subunit vaccine against feline leukaemia virus: Protective immune response in cats. Vaccine 9: 89-96. 